OPEN ACCESS

Edited by:

Athanassios Molassiotis, Aristotle University of

Thessaloniki, Greece

Reviewed by:

Xiaoyang Zhu,

South China Agricultura

University, China

Zhongxiong Lai,

Fujian Agriculture and Forestry

University, China

*Correspondence:

Jingyang $L$

jingyanglee@163.com

tThese authors have contributed equally to this work

‡ORCID:

Fei Liu

orcid.org/0000-0003-0979-9982

Specialty section:

This article was submitted to Plant Breeding,

a section of the journal

Frontiers in Plant Science

Received: 25 June 2021

Accepted: 25 August 2021 Published: 23 September 2021

Citation:

Wang X, Wang A, Li Y, Xu Y, Wei Q, Wang J, Lin F, Gong D, Liu F, Wang Y,

Peng $L$ and $L i J$ (2021) A Novel Banana Mutant "RF 1" (Musa spp. $A B B$, Pisang Awak Subgroup) for Improved Agronomic Traits and Enhanced Cold Tolerance and Disease Resistance.

Front. Plant Sci. 12:730718 doi: 10.3389/fp/s.2021.730718

\section{A Novel Banana Mutant "RF 1" (Musa spp. ABB, Pisang Awak Subgroup) for Improved Agronomic Traits and Enhanced Cold Tolerance and Disease Resistance}

\author{
Xiaoyi Wang ${ }^{1 \dagger}$, Anbang Wang ${ }^{1 \dagger}$, Yujia $\mathrm{Li}^{1+}$, Yi Xu ${ }^{1}$, Qing Wei ${ }^{1}$, Jiashui Wang ${ }^{1}$, Fei Lin ${ }^{1}$, \\ Deyong Gong ${ }^{2}$, Fei Liu ${ }^{3 \neq}$, Yanting Wang ${ }^{3}$, Liangcai Peng ${ }^{3}$ and Jingyang Li $^{1,3 *}$ \\ ${ }^{1}$ Hainan Banana Healthy Seedling Propagation Engineering Research Center, Haikou Experimental Station, Chinese \\ Academy of Tropical Agricultural Sciences, Haikou, China, ${ }^{2}$ The Fruit Tree Research Center, Institute of Subtropical Crops, \\ Guizhou Academy of Agricultural Sciences, Xinyi, China, ${ }^{3}$ Biomass and Bioenergy Research Centre, College of Plant Science \\ and Technology, Huazhong Agricultural University, Wuhan, China
}

Banana is a major fruit crop grown in tropical and subtropical regions worldwide. Among cultivars, "FenJiao, FJ" (Musa spp. ABB, Pisang Awak subgroup) is a popular variety of bananas, due to its better sugar-acid blend and relatively small fruit shape. However, because the traditional FJ variety grows relatively high in height, it is vulnerable to lodging and unsuitable for harvesting. In this study, we sought desirable banana mutants by carrying out ethyl methanesulfonate (EMS) mutagenesis with the FJ cultivar. After the FJ shoot tips had been treated with $0.8 \%$ (v/v) EMS for $4 \mathrm{~h}$, we obtained a stably inherited mutant, here called "ReFen 1" (RF1), and also observed a semi-dwarfing phenotype. Compared with the wild type (FJ), this RF1 mutant featured consistently improved agronomic traits during 5-year field experiments conducted in three distinct locations in China. Notably, the RF1 plants showed significantly enhanced cold tolerance and Sigatoka disease resistance, mainly due to a substantially increased soluble content of sugar and greater starch accumulation along with reduced cellulose deposition. Therefore, this study not only demonstrated how a powerful genetic strategy can be used in fruit crop breeding but also provided insight into the identification of novel genes for agronomic trait improvement in bananas and beyond.

Keywords: "ReFen 1" mutant, Pisang Awak (ABB), ethyl methanesulfonate (EMS)-mutagenesis, semi-dwarfing, agronomic traits, cold tolerance, sigatoka disease resistance, banana breeding

\section{INTRODUCTION}

Banana is one of the most important fruits and cash crops in tropical and subtropical regions around the world. Currently, bananas are grown in more than 130 countries, and global banana production reached ca. 125 million tons in 2017 (FAOSTAT, 2020), providing both food and income for ca. 400 million people worldwide. China is a major producer and consumer of bananas, whose harvested area and total output were 380 thousand $\mathrm{hm}^{2}$ and 11 million tons, respectively, in 2017. In particular, as one of the major banana-growing areas (Perrier et al., 2011), South China has domestically cultivated the bananas for more than 3,000 years now (Ge et al., 2005). 
However, the number of commercially grown banana varieties is relatively limited, with "Cavendish" being the dominant cultivar (de Deus et al., 2018), it accounts for more than $85 \%$ of all banana production in China.

"FenJiao, FJ" (M. paradisiaca Pisang Awak subgroup ABB), like Cavendish (M. acuminate Colla, group AAA), belongs to the Musa genus, a large herb of the family Musaceae (Cheesman, 1947). FJ is also known as a 'milk banana' in Hainan, China due to its sweet taste; it is also a desirable banana for cooking because it does not brown when cut and remains firm when cooked (Chong et al., 2011; Bi et al., 2017). Given its abiotic stressresistant properties, FJ has a stable market price (Naknaen et al., 2016) and can be grown in some subtropical regions of China (Hu et al., 2015), and its fruit can ripe quickly, distinguished by a high respiration rate and substantial ethylene production (Zhu et al., 2018b). Furthermore, FJ enjoys the dual advantages of good taste and high nutrient content (Wang et al., 2019), and its consumption is assumed to be associated with a strong reduction in the risk of colorectal cancer (Deneo-Pellegrini et al., 1996), which harbors antifungal (Ranasinghe et al., 2002) and antibacterial effects (Ono et al., 1998). However, the local FJ varieties in Hainan have disadvantages to some degree, such as higher plants, a longer growth cycle, and being vulnerable to Sigatoka disease (Huang et al., 2010; Pattison et al., 2014; Guo et al., 2015; Rames et al., 2018; Pegg et al., 2019; Shao et al., 2020), which limits the widespread cultivation of this banana plant. The traditional breeding method of genetic crossing has been applied with difficulty to dessert banana varieties, given the genetic characteristics of banana in general: parthenocarpic, polyploidy, irregular meiotic behavior, low fertility, and seed viability, among others (Heslop-Harrison and Schwarzacher, 2007; Jeridi et al., 2012; Arinaitwe et al., 2019; Batte et al., 2019). However, somatic cell mutations do not offer an effective approach for screening new varieties of banana (Bhagwat and Duncan, 1998; Karmarkar et al., 2001; Reyes-Borja et al., 2007; Uma et al., 2012; Amah et al., 2019). A mutation is, in principle, based on sudden heritable changes in the genetic material of an organism under abnormal genetic separation or recombination, such as spontaneous and induced mutations (Oladosu et al., 2015). As the incidence of spontaneous mutation is very low, physical and chemical mutagenesis agents play a pivotal role in mutagenesis (Griggs et al., 2013). In the past few decades, mutation breeding has produced thousands of new crop varieties (Sima et al., 2017). In this respect, ethyl methanesulfonate (EMS) is one of the most effective, reliable, and powerful mutagens; treating plants with EMS could destroy their nuclear DNA and randomly induce new mutations in the process of DNA repair (Greene et al., 2003; Jain, 2010). Creating new germplasm through EMS has been implemented for many crops, such as barley (Caldwell et al., 2004), rapeseed (Lee et al., 2018), potato (Moon et al., 2018), rice (Serrat et al., 2014), wheat (Wang et al., 2018), maize (Zhang et al., 2020a), and Chinese cabbage (Lu et al., 2016). Notably, Jankowicz-Cieslak et al. (2012) treated the meristem of banana stem tips with EMS and obtained high-density GC-AT base pair transition mutations, which demonstrated the high efficiency of EMS in banana germplasm innovation. Here, we used the local FJ variety in Hainan as parent material for EMS mutagenesis.
Specifically, we established a technical platform suitable for asexual reproduction and generated mutant populations of FJ, leading us to obtain a semi-dwarf mutant with stable genetic traits through screening. We termed this mutant ReFen 1 (RF1) and examined its characteristics with respect to low temperature resistance, Sigatoka disease resistance, and suitability to marginal soils. Besides finding markedly improved morphological and agronomic characteristics of RF1 mutant when grown across different ecological experimental sites, this study also provides insight into new germplasm creation via chemical mutagenesis.

\section{MATERIALS AND METHODS}

\section{Establishment of EMS Mutation Technology}

In vitro plantlets of local FJ (Xinglongnaijiao, Pisang Awak subgroup) were subjected to mutagenesis by using EMS (SigmaAldrich, Burlington, MA, USA). Proliferating shoot clusters were maintained in vitro through aseptic shoot tip cultures in Murashige and Skoog (MS) basal media (Murashige and Skoog, 1962) supplemented with $3.0 \mathrm{mg} / \mathrm{L}$ 6-benzylaminopurine (BAP), $1.0 \mathrm{mg} / \mathrm{L}$ adenine, $3.0 \mathrm{~g} / \mathrm{L}$ agarose, and $30 \mathrm{~g} / \mathrm{L}$ sucrose, at $\mathrm{pH} 5.8$. Proliferating shoot clusters received an EMS solution treatment by cutting a single isolated shoot tip, using a scalpel blade. These single shoots were incubated with EMS solution on a constant temperature $\left(27^{\circ} \mathrm{C}\right)$ rotary shaker at $120 \mathrm{rpm}$. A series of EMS solutions with different percentages of EMS was prepared using sterilized water plus $1 \%$ Tween-80, with each solution sterilized by filtration.

We expected a moderate-to-high-mutation density in the genome of progeny obtained from FJ banana mutagenesis, yet the lethality of M1 plants under a high dose of mutagen precluded producing many plantlets in a single trial. Therefore, we set up a crossed factorial experiment using a series of mutagen concentrations and immersion time gradient tests. Shoot tips were incubated for $4,8,16$, and $24 \mathrm{~h}$ in $0.4,0.8,1.2$, and $1.6 \%$ concentrations of mutagen, for a total of 16 treatment combinations. Each was inoculated with about 10 shoot tips in an Erlenmeyer flask containing $40 \mathrm{ml}$ of prepared EMS mutagen solution. After applying the treatment, shoot tips were rinsed three times in distilled water and then placed into multiplication media (as described above). Mutagenized shoot tips were transferred into fresh multiplication media every 25-60 days, depending on the differentiation of shoot tips observed. After completing six such cycles, the samples were transferred into rooting media that consisted of MS basal media supplemented with $1.0 \mathrm{~g} / \mathrm{L}$ IBA (Indole-3-Butytric acid), $3.0 \mathrm{~g} / \mathrm{L}$ agarose, and 30 $\mathrm{g} / \mathrm{L}$ sucrose, at $\mathrm{pH}$ 5.8. The survival ratio, rate of differentiation, days of differentiation, and mutation probability were recorded during this period. After plantlets were allowed to root for $40 \mathrm{~d}$, they were simultaneously acclimatized in a greenhouse for late use in field trials.

\section{Field Experiments and Plant Growth}

The agronomic trials of FJ mutants were evaluated in multiple agro-ecology sites, namely, Danzhou, Haikou, and Xingyi. At each site, the variety comparison test was carried out in an area 
of $1,250 \mathrm{~m}^{2}$, by using a randomized block trial design with three replicates. The plant spacing for these field trials was $2.5 \mathrm{~m}$ between rows and $2 \mathrm{~m}$ among plants within a row. The hardened sterile tissue culture seedlings were used as the planting seedlings, while the traditional FJ variety served as the control group. The mutant was evaluated in situ from 2014 to 2018.

\section{Observation of Plant Growth and Development}

According to the previous studies (Orjeda, 1998; Amah et al., 2019), key agronomic characteristics, namely, vegetative and yield traits, were separately evaluated at flowering time and at harvest time. The height of the pseudo-stem (HP), the pseudostem girth (PG) at $100 \mathrm{~cm}$ above the soil surface, and the plant base girth (PBG) were recorded at the time of flowering. Days to flowering (DTF) were recorded as the number of days between planting and the onset of flowering. Days to fruit filling (DTFF) were recorded as the number of days between the flowering and harvesting dates. The planting to harvest days (PTHD) was recorded as the number of days between the dates of planting and harvesting. The date of flowering was recorded upon the emergence of the flag leaf, and the date of harvest was recorded the day the banana fruits were harvested and removed from plants. Bunch weight $(\mathrm{BW})$, number of hands $(\mathrm{NH})$, the total number of fingers $(\mathrm{NF})$, fruit weight $(\mathrm{FW})$, fruit length (FL), and fruit circumference (FC) were recorded at harvest when fruits were full-bodied yet unripe (green). Fruit-related traits were collected from the middle fruit of the third hand of each bunch. At each site, 10 banana plants were randomly selected in each replicate. The harvesting criteria/steps were as follows: harvest $85 \%$ of the ripe fruit, weigh the fresh fruit after harvest, record the value of weights, subtract $10 \%$ of the fruit axis and other discarded tissues to obtain the net yield, and then derive the average value.

\section{Cold Resistance Assessment Phenotypic Observations}

For three production cycles by field natural identification method, five plants were surveyed for chilling injury at the Xingyi test site when low temperatures occurred in winter. Following the technical specifications for the cold damage assessment of bananas, the damage from chilling was recorded (Meteorological Bureau of Guangxi Zhuang Autonomous Region China, 2013). Under natural conditions, the whole plant is then typically graded for the severity of certain features: the upper part of the leaf blade and the apex of the cigar leaf have turned black and dried, or there are light-to-moderate black filaments visible in the inner layer of banana peel (Low). More than $50 \%$ of the leaves are wilted, and one-third of the cigar leaf area is damaged (Intermediate). More than $80 \%$ of the leaves are wilted and half of the cigar leaf area suffer from dry blight (High). Above-ground leaves and the cigar leaf all suffer from dry blight, having a weak or lost regenerative capacity, and die as a whole (Very high).

\section{Cell Wall Composition Assay}

The characteristics of plant cell walls may be an important factor in determining the resistance of a plant to cold (Gusta and Wisniewski, 2013). Accordingly, we tried to study the coldresistance characteristics of $R F 1, \mathrm{FJ}$, and Baxijiao (BX; Cavendish subgroup) by analyzing the differences in cell wall composition in rachis and pseudo-stems. The banana plant tissues were dried to a constant weight, ground using a grinder, and passed through a 40-mesh screen. Next, the plant cell wall fractionation method was applied, as described previously (Peng et al., 2000; Wu et al., 2013). Each banana biomass sample $(0.3 \mathrm{~g})$ was incubated with $6 \mathrm{ml}$ of potassium phosphate buffer ( $\mathrm{pH} 4.8)$ in a boiling water bath for $1 \mathrm{~h}$ and shaken every $10 \mathrm{~min}$. After centrifugation at $3,000 \times g$ for $5 \mathrm{~min}$, the supernatant was collected. Hexoses and pentoses of soluble sugars were separately detected by the colorimetric assay, as described by Li et al. (2014). After successive extractions of soluble sugars, lipids, and starch with a phosphate buffer ( $\mathrm{pH} 7.0)$, chloroform-methanol $(1: 1, \mathrm{v} / \mathrm{v})$, and (dimethyl sulfoxide, DMSO)-water $(9: 1, \mathrm{v} / \mathrm{v})$, the remaining crude cell wall pellets were incubated with $0.5 \%$ ammonium oxalate monohydrate $(\mathrm{w} / \mathrm{v})$ for $1 \mathrm{~h}$ in a boiling water bath, to extract the pectin fraction. The leftover residues were incubated with $4 \mathrm{M} \mathrm{KOH}$ (containing $1.0 \mathrm{mg} / \mathrm{ml}$ sodium borohydride) at $25^{\circ} \mathrm{C}$ for $1 \mathrm{~h}$, and their supernatants were then collected as $\mathrm{KOH}$-extractable hemicelluloses fraction after centrifugation at $4,000 \times g$. The remnant non- $\mathrm{KOH}$ extractable residues were dissolved with $\mathrm{H}_{2} \mathrm{SO}_{4}(67 \%, \mathrm{v} / \mathrm{v})$ at $25^{\circ} \mathrm{C}$, for $1 \mathrm{~h}$, and the hexose of the supernatants was then detected as the cellulose fraction (Li et al., 2021). Total hexoses and pentoses of the $\mathrm{KOH}$ extractable hemicelluloses and total pentoses of the non- $\mathrm{KOH}$ extractable fraction were summed to express the hemicellulose content level. Likewise, the total contents of hexoses, pentoses, and uronic acids were summed to derive the pectin content level. A UV-vis spectrometer (V-1100D, Shanghai MAPADA Instruments Co., Ltd. Shanghai, China) was used to detect and quantify the hexoses, pentoses, and uronic acids, as previously described (Cheng et al., 2018). A two-step acid hydrolysis method was applied to determine the lignin content of samples, and this was done according to the Laboratory Analytical Procedure of the National Renewable Energy Laboratory, as previously described (Fan et al., 2017). All the experiments were performed independently three times.

\section{Sigatoka Resistance Assessment}

Data on black Sigatoka disease were recorded over two cycles from the planting date, by using the field natural identification method (Vishnevetsky et al., 2011), the field identification of the trial varieties ( $R F 1, \mathrm{FJ}$, and Baxijiao), the whole year does not use any fungicide. Ten plants were randomly selected to investigate the disease severity of each plant; for this, the youngest leaf with at least 10 necrotic spots at flowering (youngest leaf spotted, YLS), number of standing leaves at flowering (NSL) were recorded, from which the index of non-spotted leaves (INSL) (Orjeda, 1998; Smith et al., 2018) was calculated this way:

$$
\mathrm{INSL}=\frac{\mathrm{YSL}-1}{\mathrm{NSL}} \times 100
$$

\section{Banana Fruit Quality Assay}

Bananas fruits were harvested at the mature green stage. When the fruit was fully ripe (i.e., the color of the peel was bright 
yellow), the fruit quality was analyzed. To do this, several chemical properties-reducing sugar (RS), total sugar (TS), vitamin $\mathrm{C}$ (VC), total titratable acidity (TA), and crude protein (CP) - were determined by following the procedures used in other reported research (Workneh et al., 2012; Tigist et al., 2013; Altemimi et al., 2017; Yap et al., 2017). Briefly, an aliquot of banana juice was obtained using a juice extractor and filtered through gauze. The ensuing clear juice was used for further analyses. Using the method described by Tigist et al. (2013), the RS and TS values of banana juice were measured with a refractometric saccharometer (ATAGO ${ }^{\circledR}$ MASTER-53T). The VC content was measured by the 2, 6-dichlorophenolindophenol method (AOAC, 1990), for which a 10-ml banana juice extract was diluted to $50 \mathrm{ml}$ with $3 \%$ met phosphoric acid in a 50 $\mathrm{ml}$ volumetric flask. This was then centrifuged at $10,000 \times \mathrm{g}$ for $15 \mathrm{~min}$, followed by titration with standard dye to a pink end point for $15 \mathrm{~s}$; ascorbic acid content (\%) was calculated according to the titration value, dye factor, dilution factor, and volume of the sample. The TA of banana was quantified as described by Yap et al. (2017), in which diluted banana pulp was titrated with 0.1 mol/L $\mathrm{NaOH}$. After adding each $\mathrm{NaOH}$ drop, the Erlenmeyer flask was rotated until the color disappeared, faded, or stayed the same after $\sim 1 \mathrm{~min}$ of rotating. TA was calculated in grams of malic and citric acid per $100 \mathrm{ml}$. CP content was determined using the Kjeldahl method, as described by Zhu et al. (2018a).

The ratio of sugar to acid (RSTA) was calculated as follows:

$$
\text { RSTA }=\frac{\text { Total sugar }(\mathrm{TS})}{\text { Total titratable acidity (TA) }}
$$

Potassium, zinc, and iron concentrations were quantified using the flame photometric method. The ash of each banana

TABLE 1 | Banana shoot growth and development after treatment with EMS.

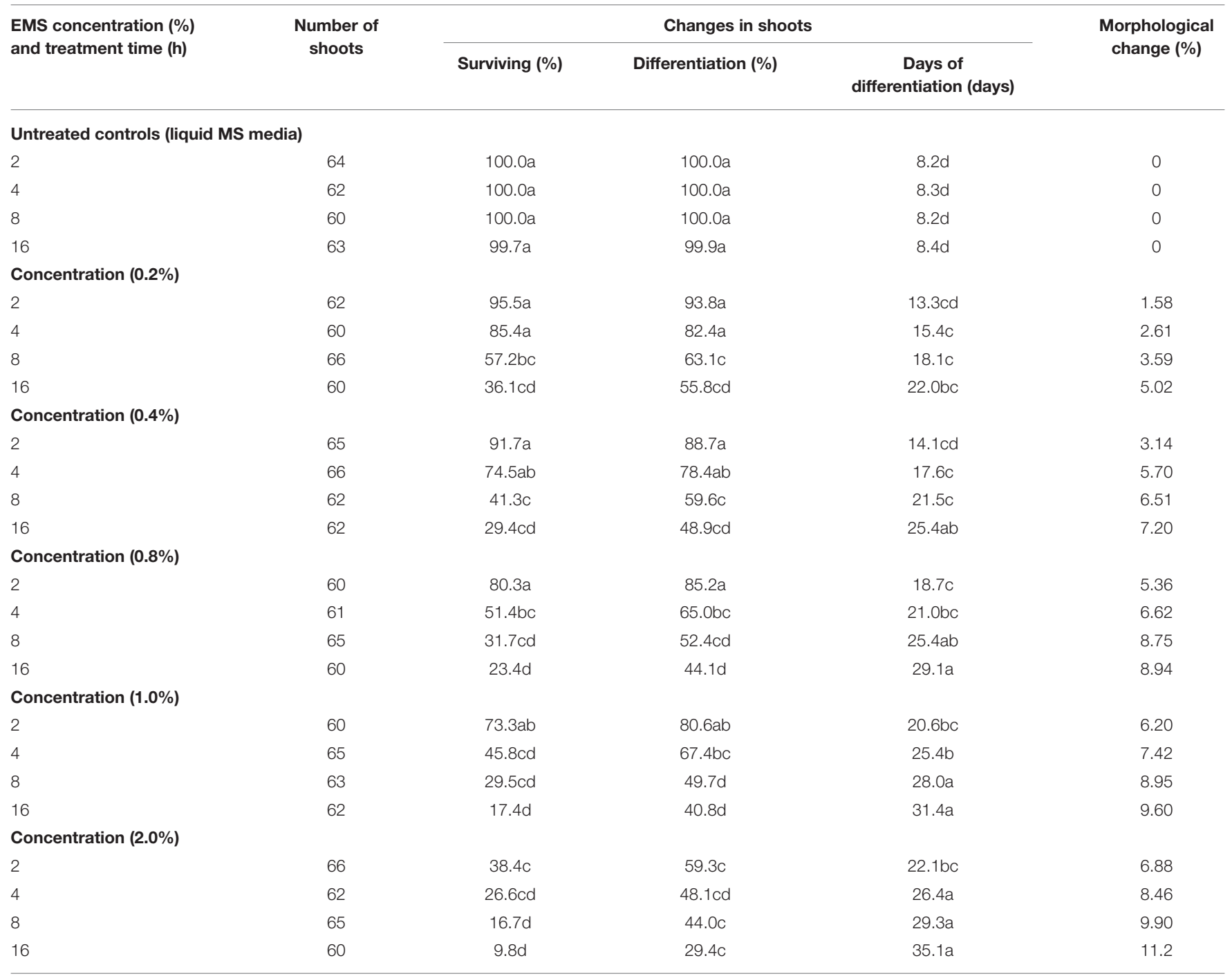

Statistical significance was assessed using two-way ANOVAs. Within columns, differing lowercase letters indicate mean values that are significantly different. EMS, ethyl methanesulfonate; MS, Murashige and Skoog. 
sample was digested with nitric acid on a hot plate. Then the samples were aspirated into the flame and measurements were made with an atomic absorption spectrophotometer (Aanalyst401, Spectrometer, Perkin Elmer, Waltham, MA, USA) equipped with different lamps for the different mineral elements.

\section{Data Collection and Statistical Analysis}

The results are expressed as the mean \pm SD or median of at least three independent experiments. Differences were considered significant at $p<0.05$. Differences between treatment combination groups were assessed using a one-way ANOVA with a post-hoc Least Significant Difference test (LSD) $t$-test, or a two-way ANOVA followed by an LSD-multiple comparisons test, implemented in Sigma Plot 14.0 (Systat Software, San Jose, CA, USA). The 10 plant traits of RF1 and FJ were used as input values for a principal component analysis (PCA), to check for similarities and differences in agronomic/physiological traits among the samples, this was performed in Origin 2018 software (Origin Lab Corporation, Northampton, MA, USA).

\section{RESULTS}

\section{Selection of EMS-Induced Mutant With Local Banana Cultivar (FJ)}

We examined whether EMS could induce lethal mutagenesis in banana shoot cultures of the local banana cultivar FJ. First, a chemical mutation culture system suitable for FJ was established for mutant screening. Then the toxicity of EMS was inferred from the survival rate and differentiation time of banana proliferation shoots under different combinations of mutagen concentrations and soaking times. The two-way ANOVA results revealed significant effects of EMS concentration, treatment time, and their interaction on mutagen-induced plant responses (Table 1). A significant reduction in the survival rate was observed with an increasing EMS concentration and longer treatment time $(p<$ 0.05; Supplementary Figure 1). Lethal dose $50\left(\mathrm{LD}_{50}\right)$ is defined as the EMS concentration and treatment time that results in $50 \%$ lethality (Arisha et al., 2015). Generally, $\mathrm{LD}_{50}$ is used as a parameter to produce a high mutation frequency (Hohmann et al., 2005). When the mutagen concentration was higher than $0.8 \%$ and soaked for more than $4 \mathrm{~h}$, the survival rate of M1 was significantly low, at $<50 \%$ (Table 1; Supplementary Figure 1). Therefore, the $\mathrm{LD}_{50}$ value of EMS mutagen with FJ was estimated to be ca. $0.8 \%$ under a 4 -h soaking.

Furthermore, the EMS-induced mutation with FJ showed large variation, especially for the incidence of total morphological change, which varied from 1.58 to $11.2 \%$. For instance, white leaf stripe, Xantha, chlorine, and dwarfism were frequently observed in mutants. These mutants were then planted in fields, and we found that a semi-dwarf mutant, here termed RF1, had excellent agronomic traits among all the mutants examined.

\section{Altered Morphological and Botanical Characteristics in RF1 Mutant}

To characterize the RF1 mutant, we observed that the pseudostem of RF1 was dwarfed and the pseudo-stem girth became thicker, compared to the FJ cultivar (i.e., the wild type/control).

TABLE 2 | Major agronomic traits of RF1 and FJ at multiple field sites.

\begin{tabular}{|c|c|c|c|c|c|c|c|c|}
\hline Test sites & Variety & Date & DTF (days) & DTFF (days) & PTHD (days) & $\mathrm{HP}(\mathrm{cm})$ & PBG (cm) & $P G(\mathrm{~cm})$ \\
\hline \multirow[t]{5}{*}{ Danzhou } & RF 1 & FS & $347.9 \mathrm{c}$ & $72.0 a$ & $421.0 a$ & $317.5 a$ & $108.5 a$ & $75.0 \mathrm{a}$ \\
\hline & & $\mathrm{FR}$ & $336.7 \mathrm{~b}$ & $70.3 a$ & $409.0 a$ & $312.5 a$ & $112.5 a$ & $79.0 a$ \\
\hline & & SR & $329.9 a$ & $70.5 a$ & $406.0 a$ & $306.5 a$ & $112.0 \mathrm{a}$ & $80.0 a$ \\
\hline & FJ & FS & $373.2 f$ & $76.2 \mathrm{a}$ & $452.0 \mathrm{~b}$ & $467.0 \mathrm{~b}$ & $95.0 \mathrm{~b}$ & $59.0 b$ \\
\hline & & $\mathrm{FR}$ & $359.0 d$ & $76.5 a$ & $431.0 a$ & $455.0 \mathrm{~b}$ & $101.5 a$ & $64.0 \mathrm{~b}$ \\
\hline & & FR & $336.7 \mathrm{~b}$ & $76.1 \mathrm{a}$ & 413.0a & $305.5 a$ & $109.0 a$ & $78.0 \mathrm{a}$ \\
\hline & & SR & $328.9 a$ & $71.6 a$ & $400.5 a$ & 309.0a & $111.5 a$ & $79.0 a$ \\
\hline & FJ & FS & $382.3 \mathrm{~g}$ & $91.5 b$ & $472.0 \mathrm{~b}$ & $461.0 \mathrm{~b}$ & $90.5 b$ & $70.0 \mathrm{~b}$ \\
\hline & & FR & $366.3 \mathrm{e}$ & $90.2 b$ & $455.0 \mathrm{~b}$ & $454.5 b$ & $92.5 b$ & $71.5 b$ \\
\hline & & SR & $357.8 d$ & $87.7 b$ & $444.5 b$ & $454.5 b$ & $95.0 \mathrm{~b}$ & $72.0 \mathrm{~b}$ \\
\hline & FJ & FS & $414.7 j$ & $88.5 b$ & $502.0 \mathrm{~b}$ & $449.5 b$ & $89.5 b$ & $66.0 \mathrm{~b}$ \\
\hline & & $\mathrm{FR}$ & $395.1 \mathrm{i}$ & $90.0 b$ & $485.0 \mathrm{~b}$ & $446.5 b$ & $92.0 \mathrm{~b}$ & $67.5 b$ \\
\hline & & SR & 388.6h & $88.6 \mathrm{~b}$ & $478.5 b$ & $441.0 \mathrm{~b}$ & $92.0 \mathrm{~b}$ & $62.0 \mathrm{~b}$ \\
\hline
\end{tabular}

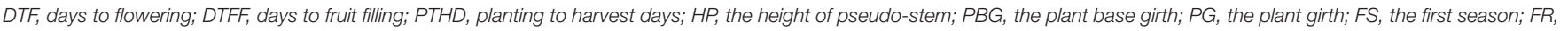
the first ratoon; $S R$, the second ratoon.

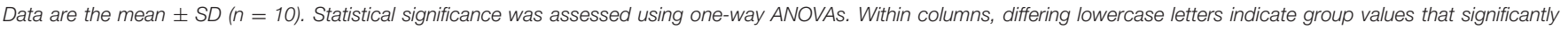
different (one-way ANOVA, $p<0.05$ ), according to a pairwise multiple comparison procedures (Tukey's test). 

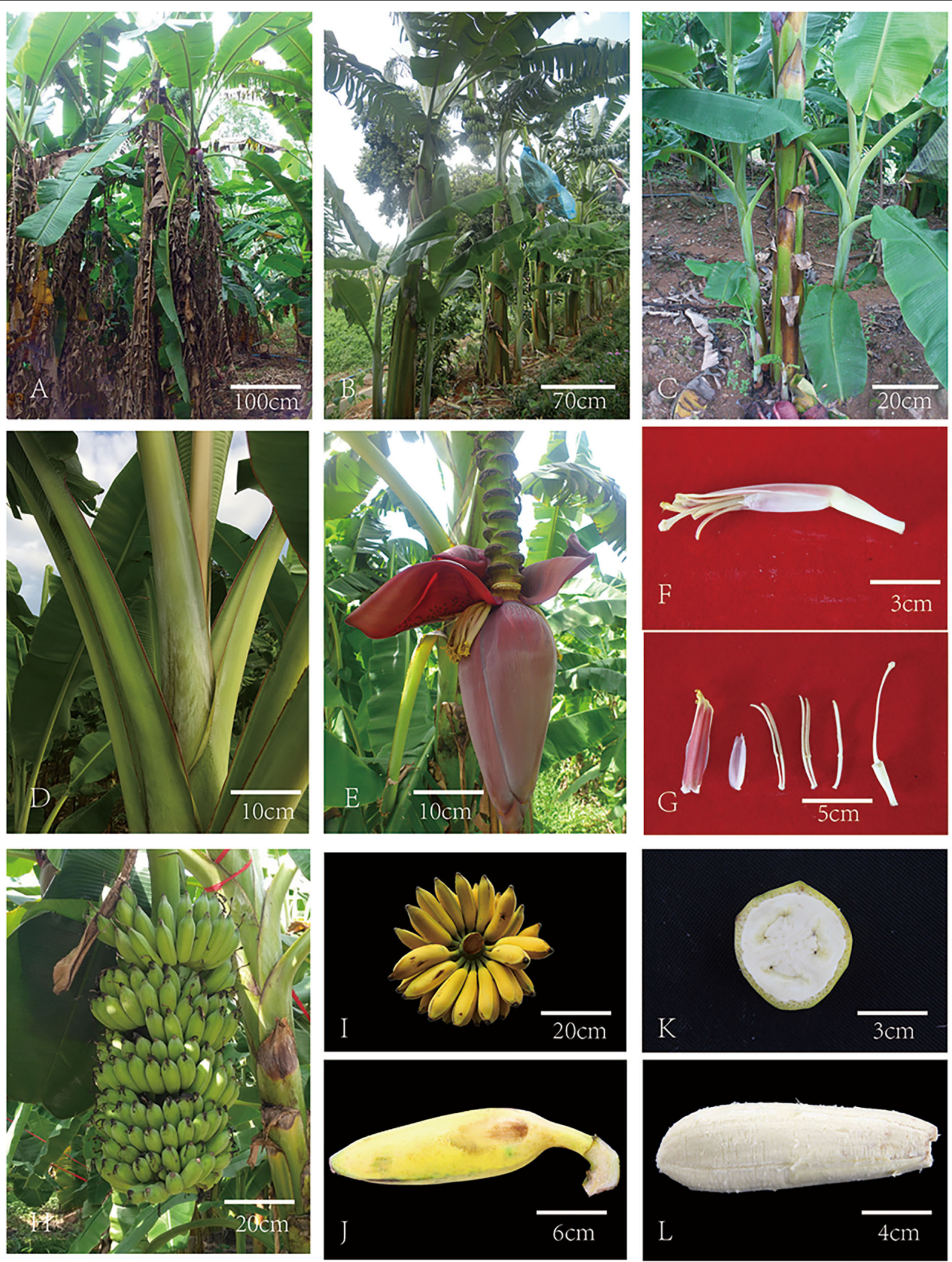

FIGURE 1 | Morphological observations of the 'RF1' mutant. (A,B) FJ (bar $=100 \mathrm{~cm})$ and RF1 (bar $=70 \mathrm{~cm})$ phenotypes. (C,D) RF1 suckers (bar $=10 \mathrm{~cm})$ and petiole (bar $=20 \mathrm{~cm})$. (E,F) RF1 male bud (bar $=10 \mathrm{~cm}$ ) and male flower (bar $=3 \mathrm{~cm})$. (G) $R F 1$ compound tepal, free tepal, filament $\times 3$, ovary and style (from left to right, respectively). Bar $=5 \mathrm{~cm}$. (H) $R F 1$ bunch on the tree. Bar $=20 \mathrm{~cm}$. (I) $R F 1$ mature fruit. Bar $=20 \mathrm{~cm}$. (J) $R F 1$ fruit shape. Bar $=6 \mathrm{~cm}$. (K) Arrangement of ovules of $R F 1$ fruit. Bar $=3 \mathrm{~cm}$. (L) $R F 1$ fruit pulp. Bar $=4 \mathrm{~cm}$. RF1, ReFen 1; FJ, FenJiao. 
The height of pseudo-stem (HP) was decreased by $32 \%$, while the PG was increased by $25.2 \%$ at the $p \leq 0.05$ level (Table 2). The mature $R F 1$ mutant had a pseudo-stem height of $3.0-3.2 \mathrm{~m}$, with a $70-80 \mathrm{~cm}$ circumference at a height of $100 \mathrm{~cm}$ from the ground, and it was covered with a small amount of wax powder (Table 2 and Figures 1A,B). Suckering was close to the parent plant 5$50 \mathrm{~cm}$, to $8-11$ suckers, which grew vertically (Figure 1C). The lamina oblong reached $180-220 \mathrm{~cm}$ in length and $48-60 \mathrm{~cm}$ in width, and the midrib was yellowish-green, suborbicular at the base. Petiole length was $38-60 \mathrm{~cm}$, and leaf sheaths were at green, smooth, and margin incurved by $2-3 \mathrm{~cm}$ from both sides of petiole edge (Figure 1D). The bracts lilac was outside, and the inner surface vermillion was $18-30 \mathrm{~cm}$ long, deciduous, with 12-20 flowers per bract, double rowed (Figures 1E,F). The compound petals were $5.8-6.5 \mathrm{~cm}$ long, yellow-purple, the lateral ones narrow; free petals were $2.5-3.2 \mathrm{~cm}$ long, translucent, pale-purple, boat-shaped, with stamens light yellow (Figure 1G). Inflorescence pendulous was $80-120 \mathrm{~cm}$ long, and its peduncle and rachis shortly and softly pubescent, arranged in a spiral hand and composed of 5-15 hands, each with 12-24 fruits at $11-22 \mathrm{~cm}$ long. Fruit pedicel was at $1.8-2.0 \mathrm{~cm}$ long, glabrous (Figures 1H-J). The circumference was $8-15 \mathrm{~cm}$, with slightly curved fingers. The fruit apex was obtuse, and the cross-section of the fruit had five-sided angles (Figure 1K). The peel was green, pericarp at $1.0-1.5 \mathrm{~mm}$, ripening yellow, and the pulp cream in color (Figures 1K,L). Finally, this study confirmed that RF1 fruits were seedless. Hence, the RF1 mutant featured markedly altered morphological and botanical properties when compared to the FJ cultivar.

\section{Improved RF1 Agronomic Traits}

This study further compared RF1 and FJ in the Danzhou experimental field from 2014 to 2017 for the testing of two ratoons (Table 3). The RF1 mutant showed a significantly increased BW by $18.7 \%$, on average, when compared to $\mathrm{FJ}$ ( $p \leq$ 0.05 ) in the first season (FS), while the BW was $20.8 \%$ higher of $R F 1$ than $\mathrm{FJ}$ in the first ratoon (FR) with a $21.5 \%$ increase in BW in the second ratoon (SR) test ( $p \leq 0.05$; Table 3 ). Accordingly, the RF1 mutant displayed significantly increased BW, FW, FL, and FC, all at $p \leq 0.05$ (Table 3). Additionally, the RF1 had significant advantages in growth cycles, in which DTF, DTFF, and PTHD were shortened by 24, 5, and $27 \mathrm{~d}$ at $p \leq 0.05$, respectively (Table 2 ).

Furthermore, a PCA comprehensively evaluated HP, PBG, PG, DTF, DTFF, BW, NH, NF, FW, FL, and FC between the RF1 mutant and FJ cultivar, to screen the agronomic/physiological traits responsible for the variable discrimination (Tables 2, 3). This showed that two principal components (PCs) together explained $75.6 \%$ of the variance in the whole data set (PC1: 64.4\%; PC2: 11.2\%; Figure 2). The distribution of traits along the two components (PC1 and PC2) is shown in Figure 2. The traits PBG, $\mathrm{FL}, \mathrm{BW}, \mathrm{FW}, \mathrm{FC}$, and PG were associated with RF1, whereas $\mathrm{HP}$ and DTF were associated with FJ. Meanwhile, the NH, NF, and DTFF traits did not differ between the RF1 mutant and FJ cultivar. These results suggested that $R F 1$ offers great advantages in terms of plant growth and development.

In addition, agronomic trials of RF1 mutant were conducted and evaluated from 2014 to 2018 in multiple agro-ecology sites by Danzhou, Haikou, and Xingyi (Supplementary Figure 2

TABLE 3 | Yield assessment of RF1 and FJ at multiple field sites.

\begin{tabular}{|c|c|c|c|c|c|c|c|c|}
\hline Test site & Variety & Harvest date & BW (kg) & NH & NF & FW (g) & FL (cm) & $\mathrm{FC}(\mathrm{cm})$ \\
\hline \multirow[t]{6}{*}{ Danzhou } & $R F 1$ & FS & $24.8 \mathrm{c}$ & $10.5 a$ & $200.5 c$ & $123.8 \mathrm{a}$ & $15.5 a$ & $15.6 a$ \\
\hline & & FR & $27.3 a$ & $12.0 \mathrm{a}$ & $218.9 a$ & $130.8 \mathrm{a}$ & $15.5 a$ & $15.5 a$ \\
\hline & & $\mathrm{SR}$ & $27.1 \mathrm{a}$ & $12.0 \mathrm{a}$ & $220.4 a$ & $130.1 a$ & $15.7 a$ & $15.9 a$ \\
\hline & FJ & FS & $20.9 f$ & $10.0 b$ & $190.2 d$ & $106.1 b$ & $13.3 b$ & $13.4 b$ \\
\hline & & $\mathrm{FR}$ & $22.6 \mathrm{e}$ & $12.0 \mathrm{a}$ & $211.4 b$ & 112.0b & $13.2 b$ & $13.4 b$ \\
\hline & & $\mathrm{SR}$ & $22.3 \mathrm{e}$ & $12.0 \mathrm{a}$ & $216.5 a$ & $110.6 b$ & $13.6 b$ & $13.7 b$ \\
\hline \multirow[t]{6}{*}{ Haikou } & $R F 1$ & FS & $25.2 c$ & $11.0 \mathrm{a}$ & $197.9 c$ & $128.0 \mathrm{a}$ & $15.9 a$ & $16.0 \mathrm{a}$ \\
\hline & & FR & $27.0 a$ & $11.0 \mathrm{a}$ & $195.4 c$ & $135.0 \mathrm{a}$ & $16.0 \mathrm{a}$ & $16.3 a$ \\
\hline & & SR & $26.5 b$ & $12.0 \mathrm{a}$ & $199.9 c$ & $134.0 \mathrm{a}$ & $16.0 \mathrm{a}$ & $16.2 \mathrm{a}$ \\
\hline & FJ & FS & $21.6 \mathrm{e}$ & $11.0 \mathrm{a}$ & $194.8 c$ & $110.5 b$ & $13.5 b$ & $13.9 b$ \\
\hline & & $\mathrm{FR}$ & $22.0 \mathrm{e}$ & $11.0 \mathrm{a}$ & 193.1c & $109.5 b$ & $13.9 b$ & $14.0 \mathrm{~b}$ \\
\hline & & $\mathrm{SR}$ & 21.0f & $11.0 \mathrm{a}$ & $189.6 d$ & $110.5 b$ & $14.1 b$ & $14.3 b$ \\
\hline \multirow[t]{6}{*}{ Xingyi } & RF1 & FS & $22.0 \mathrm{e}$ & $11.0 \mathrm{a}$ & $196.4 \mathrm{c}$ & $119.5 a$ & $15.5 a$ & $16.0 \mathrm{a}$ \\
\hline & & FR & $23.7 d$ & $11.0 \mathrm{a}$ & $195.6 c$ & $125.5 a$ & $15.9 a$ & $16.0 a$ \\
\hline & & $\mathrm{SR}$ & $22.9 \mathrm{e}$ & $12.0 \mathrm{a}$ & 201.2c & $125.5 a$ & $15.9 a$ & $16.0 a$ \\
\hline & FJ & FS & $18.5 \mathrm{~g}$ & $11.5 a$ & $196.6 c$ & $108.5 b$ & $13.9 b$ & $14.0 \mathrm{~b}$ \\
\hline & & $\mathrm{FR}$ & $20.4 f$ & $11.0 \mathrm{a}$ & $200 c$ & $113.5 b$ & $13.8 b$ & $14.0 \mathrm{~b}$ \\
\hline & & $\mathrm{SR}$ & $20.7 f$ & $11.0 \mathrm{a}$ & $197.5 c$ & $113.5 b$ & $13.9 b$ & $14.0 \mathrm{~b}$ \\
\hline
\end{tabular}

BW, bunch weight; NH, number of hands; NF, total number of fingers; FW, fruit weight; FL, fruit length; FC, fruit circumference.

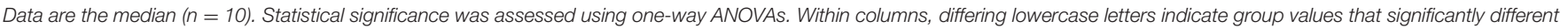
(one-way ANOVA, $p<0.05$ ), according to a pairwise multiple comparison procedures (Tukey's test). 


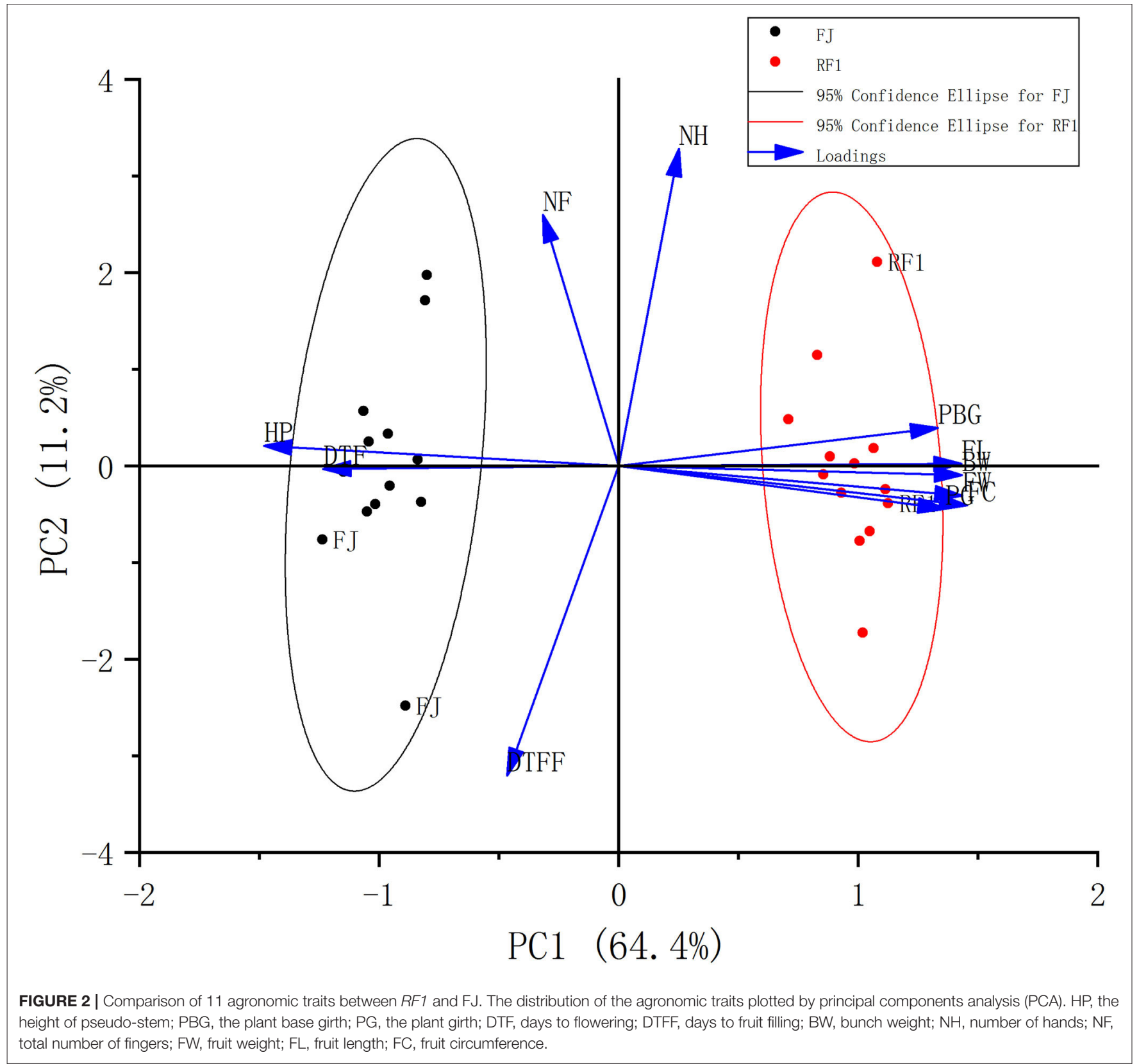

and Supplementary Table 1). These results indicated that the plant growth of the RF1 mutant was similar between Haikou and Danzhou. By contrast, their DTF, DTFF, and BW of RF1 mutant were all significantly different between Hainan and Xingyi. The altitude of Xingyi exceeds that of Haikou and Danzhou (Supplementary Figure 2), and so the annual mean temperature in Xingyi is $7^{\circ}-9^{\circ}$ lower than that in Hainan (Supplementary Table 1). In Xingyi, plants incurred cold injury when temperatures reached as low as $1^{\circ} \mathrm{C}$ for 3 d. Banana is suitable for planting at $20-35^{\circ} \mathrm{C}$ and is severely affected by low temperature, growing poorly at below $10^{\circ} \mathrm{C}$. Therefore, based on our results, we speculated that perhaps the low temperature not only caused the extension of the DTF and fruit filling but also led to a reduction in fruit production.

\section{Altered RF1 Fruit Nutrient Composition}

In terms of the fruit quality of $R F 1$ mutant, this study determined its skin color, shape, size, nutrient content, sweetness, and flavor, etc. (Wyatt et al., 2015). Compared with the FJ cultivar, the RF1 mutant showed a significantly increased RS content but had reduced TS levels and TA, at $p \leq 0.01$ (Figure 3 ). However, the RF1 mutant contained CP and VC levels similar to those present in the FJ. Given that the RSTA is an important indicator that can affect the taste and quality of fruit (Zhang et al., 2020b), here we uncovered that $R F 1$ produced bananas of delicate flesh 


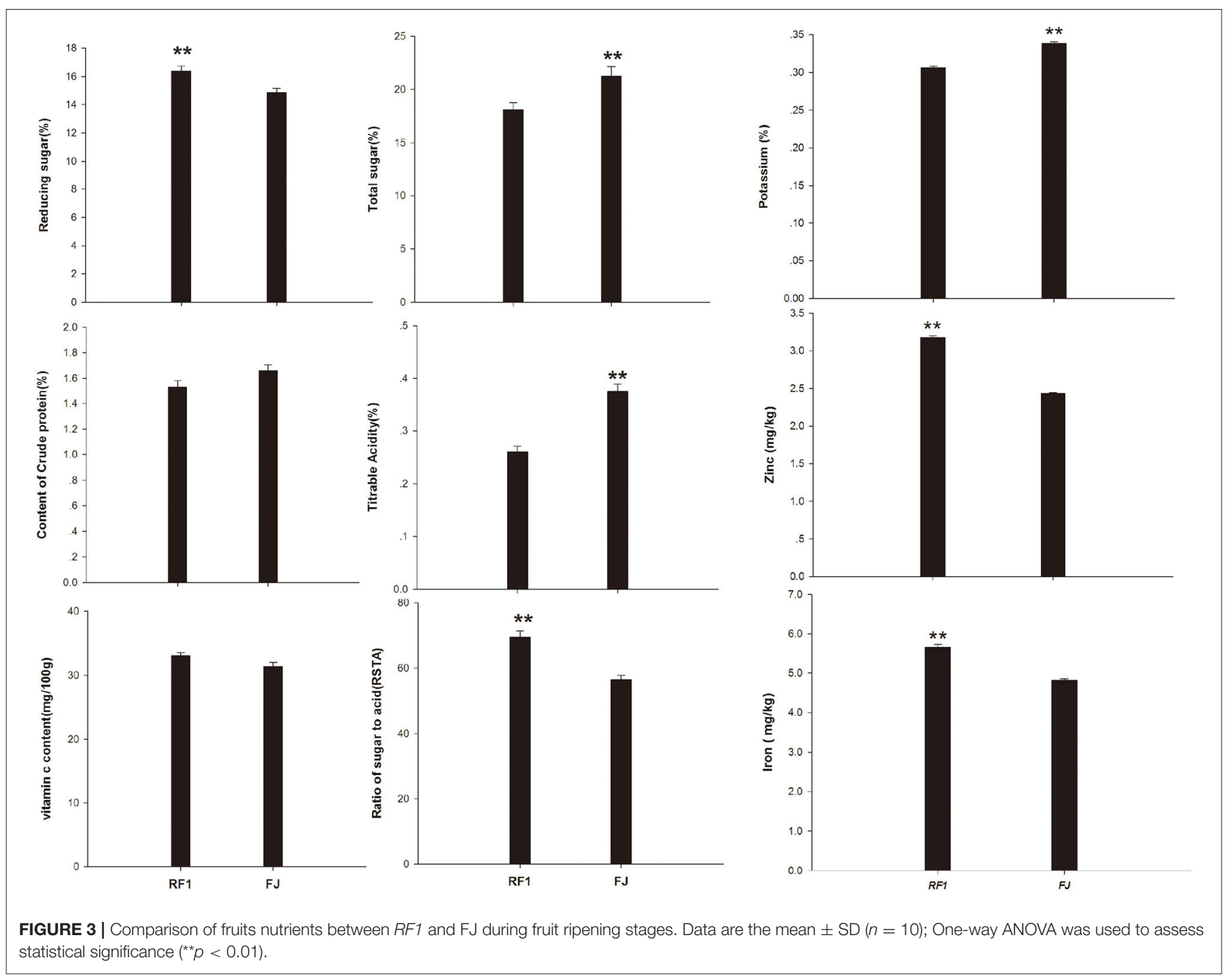

and moderately sweet and sour, whose TS content was $3.17 \%$ (lower than FJ); however, TA content of FJ was $0.12 \%$ higher than that of $R F 1$, therefore, the RSTA of $R F 1$ was significantly higher (reaching 12.96) than that of FJ at $p \leq 0.01$. Further, this study found that the RF1 mutant contained more zinc and iron whereas the FJ had a higher level of potassium content.

\section{Enhanced RF1 Tolerance to Cold and Resistance to Disease}

Banana is suitable for planting in tropical and subtropical regions, as it is highly susceptible to chilling injury. Accordingly, this study investigated the tolerance of RF1 to cold conditions. In the winter of 2014, at the Xingyi plot (Guizhou Province) there was a sudden drop in temperatures that reached as low as $1^{\circ} \mathrm{C}$ for $3 \mathrm{~d}$, during which time we observed that the $R F 1$ blade did not have any cold injury syndromes, producing normal flower buds (Figure 4A). In contrast, the FJ cultivar exhibited mild injury symptoms in its blade, and another cultivar Baxijiao displayed severe chilling symptoms in the whole plant, leading to death (Figures 4B,C).

Low temperatures usually induce extracellular ice formation, which results in cell deformation and chilling damage in plants (Takahashi et al., 2021). The contents of soluble sugar, proline, soluble protein, and the cell wall composition will together strongly influence the extent and magnitude of cell deformation induced by chilling damage (Pearce, 1988; Xu et al., 2010; Takahashi et al., 2021). Therefore, to understand why the RF1 mutant was capable of high cold resistance, we examined its cell wall composition and other components of pseudo-stem and rachis tissues (Table 4). Compared with the two control cultivars (FJ and $\mathrm{BX}$ ), the RF1 mutant contained 2-8 times higher levels of soluble sugars and starch in both its pseudo-stem and rachis tissues (Figure 4D), which could be a major factor explaining its enhanced cold resistance. Notably, the BX cultivar contained the lowest levels of soluble sugars and starch, accounting for its most injury of the whole plant. Further, in the pseudo-stem tissues, the cellulose level of the $R F 1$ mutant was relatively reduced vis-à-vis 


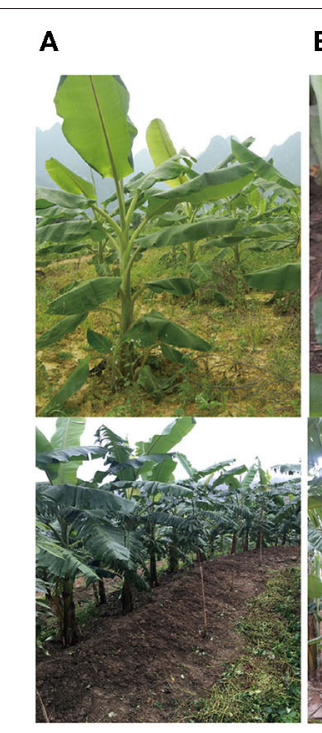

RF1
B

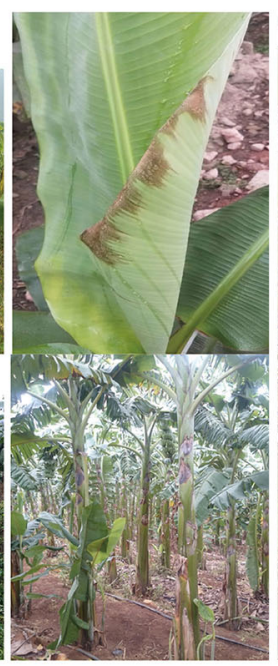

FJ
C

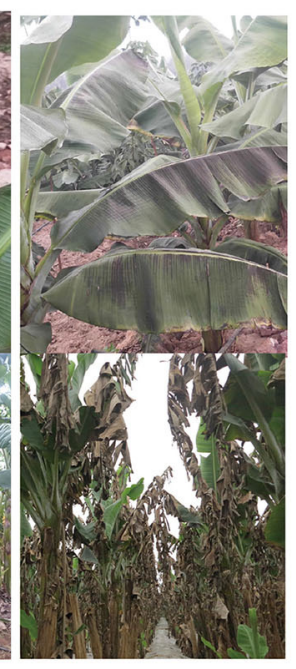

$B X$
D

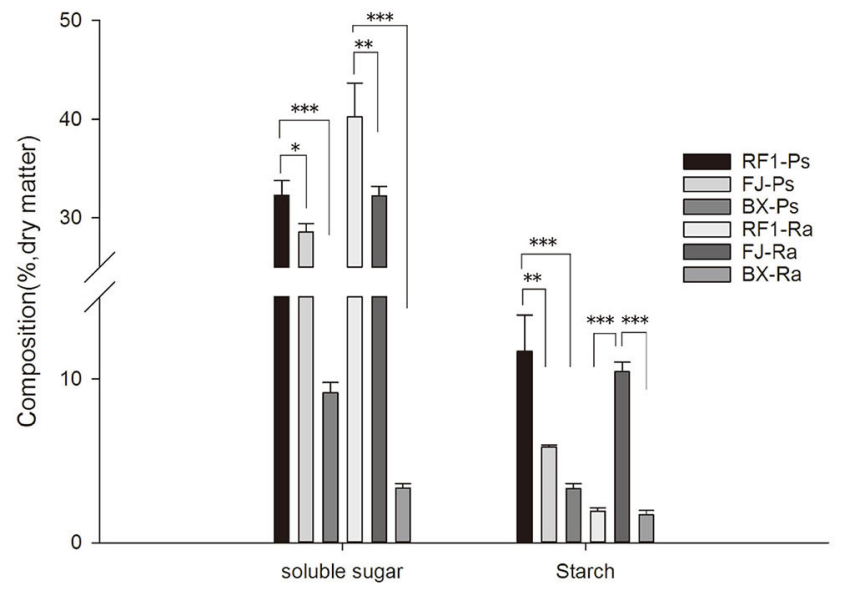

FIGURE 4 | Phenotype observations of cold tolerance and assessment of carbohydrate accumulation in RF1 mutant and cultivars (FJ and BX). (A-C) Leaf phenotypes during growth in winter at the Xingyi test site. The top images of the leaf were taken after 3 days of chilling injury. The bottom images of the leaf were taken after 14 days of chilling injury. (D) Contents of soluble sugar and starch in the pseudo-stem and rachis. Data are the mean \pm SD ( $n=3$ ); One-way ANOVA test was used to assess statistical significance $\left({ }^{\star} p<0.05 ;{ }^{\star \star} p<0.01 ;{ }^{\star \star *} p<0.001\right)$.

TABLE 4 | Cell wall composition (\% dry matter) of pseudo-stem and rachis tissues in the RF1 and FJ samples.

\begin{tabular}{|c|c|c|c|c|c|c|c|}
\hline Samples & Soluble sugar & Starch & Pectin & Cellulose & Hemicellulose & Lignin & Ash \\
\hline RF1-Ps\# & $34.3 \pm 1.600 b$ & $15.0 \pm 0.610 a$ & $5.7 \pm 0.203 a$ & $27.5 \pm 0.499 c$ & $12.2 \pm 0.420 b$ & $7.9 \pm 0.548 e$ & $1.4 \pm 0.0642 d$ \\
\hline FJ-PS & $28.7 \pm 0.696 d$ & $5.8 \pm 0.239 c$ & $5.9 \pm 0.247 a$ & $35.5 \pm 0.694 b$ & $11.9 \pm 0.689 b$ & $10.8 \pm 0.698 c$ & $1.7 \pm 0.125 c$ \\
\hline BX-Ps & $10.6 \pm 0.624 \mathrm{e}$ & $4.4 \pm 0.501 d$ & $5.1 \pm 0.462 a b$ & $38.7 \pm 2.115 a$ & $15.1 \pm 0.266 a$ & $12.6 \pm 0.317 b$ & $2.1 \pm 0.149 b$ \\
\hline $\mathrm{RF} 1-\mathrm{Ra}^{*}$ & $45.4 \pm 0.380 a$ & $2.4 \pm 0.36 e$ & $3.8 \pm 0.427 b$ & $24.1 \pm 1.700 d$ & $10.4 \pm 0.138 c$ & $9.3 \pm 0.884 d$ & $3.5 \pm 0.164 a$ \\
\hline FJ-Ra & $31.3 \pm 0.336 c$ & $10.2 \pm 0.413 b$ & $4.1 \pm 0.224 b$ & $28.4 \pm 1.423 c$ & $10.6 \pm 0.518 c$ & $11.5 \pm 0.319 c$ & $3.4 \pm 0.110 a b$ \\
\hline $\mathrm{BX}-\mathrm{Ra}$ & $5.03 \pm 0.446 f$ & $2.8 \pm 0.275 e$ & $3.9 \pm 0.425 b$ & $21.2 \pm 2.240 \mathrm{e}$ & $12.8 \pm 0.352 b$ & $15.5 \pm 0.240 a$ & $3.7 \pm 0.103 a$ \\
\hline 95\% LSD & 2.902 & 1.695 & 0.620 & 2.826 & 0.773 & 0.982 & 0.220 \\
\hline
\end{tabular}

${ }^{\#} P$ s, pseudo-stem; *Ra, rachis.

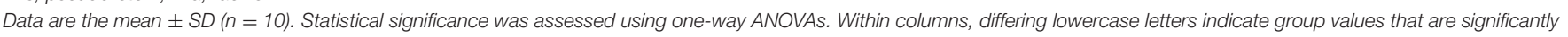
different (one-way ANOVA, $p<0.05$ ).

the FJ and BX cultivars. Taken together, these results indicated that the carbon partitioning processes were likely altered in the RF1 mutant via regulation of starch-sucrose metabolisms.

Sigatoka leaf spot disease, caused by Mycosphaerella fijiensis, has become the most damaging disease impacting banana crops worldwide (Vishnevetsky et al., 2011). The development of banana varieties with Sigatoka disease resistance is currently the dominant strategy for improving tolerance to Sigatoka. Accordingly, this study also evaluated the resistance of RF1 to Sigatoka disease in different experimental fields (Table 5). Field observations of 2-year experiments showed that the RF1 mutant has significantly improved quantitative traits, such as YLS, NSL, and INSL at $p<0.05$, when compared to the FJ cultivar (Table 5). These results indicated the RF1 mutant harbors relatively high resistance to Sigatoka disease, which is a major biotic problem limiting banana growth and development.

\section{DISCUSSION}

Traditional genetic breeding has struggled to improve major agronomic traits and stress resistance in bananas, mainly due to its parthenocarpy and polyploidy (Ortiz and Swennen, 2014; Amah et al., 2019). Therefore, mutation breeding using in vitro propagated bananas has been proposed as a powerful approach to develop new cultivars or improved strains based on excellent cultivars (Karmarkar et al., 2001; Saraswathi et al., 2016; Datta et al., 2018). The mutagenic frequency of progenies can be increased to ca. $11 \%$, a level 100 times that of the natural (background) mutagenic frequency (Karmarkar et al., 2001). In this study, we used chemical mutagens to treat adventitious buds in banana plants, which can greatly increase the overall mutagenic efficiency. Our study was able to generate a wide range of mutation types, well-beyond that which occurs under natural variation. 
TABLE 5 | Comparison of banana resistance to Sigatoka disease in RF1 and FJ grown at two experimental filed sites.

\begin{tabular}{|c|c|c|c|c|c|c|c|}
\hline Test site & Harvest year & \multicolumn{3}{|c|}{ RF1 } & \multicolumn{3}{|c|}{ FJ } \\
\hline Haikou & $\mathrm{FR}$ & $3.4 \pm 0.516 a$ & $8.8 \pm 0.632 a$ & $27.3 \pm 5.753 a$ & $4.1 \pm 0.568 b$ & $7.8 \pm 0.422 b$ & $40.0 \pm 8.593 b$ \\
\hline \multirow[t]{2}{*}{ Xingyi } & FS & $2.7 \pm 0.675 a$ & $10.0 \pm 0.943 a$ & $17.1 \pm 6.815 a$ & $2.8 \pm 0.632 b$ & $8.9 \pm 0.738 b$ & $27.1 \pm 6.008 b$ \\
\hline & $\mathrm{FR}$ & $3.4 \pm 0.516 a$ & $8.9 \pm 0.738 a$ & $20.3 \pm 7.081 a$ & $3.5 \pm 0.527 b$ & $7.6 \pm 0.516 b$ & $33.2 \pm 8.213 b$ \\
\hline
\end{tabular}

YLS, youngest leaf with at least 10 necrotic spots at flowering (youngest leaf spotted); NSL, number of standing leaves at flowering (NSL); INSL, the index of non-spotted leaves.

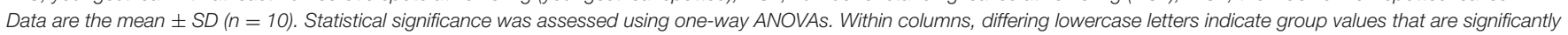
different (one-way ANOVA, $p<0.05)$.

Research shows that when using mutagens in a high concentration, both the toxicity and physiological damage to recipient plants are relatively increased, which often affects their rate of survival (Gao et al., 2018; Samatadze et al., 2019). Conversely, when treating plants with a low concentration of mutagen for a long time at low temperature, the damage to chemicals in cells is limited, because the low temperature confers to chemicals certain stability, and the low concentration has little or negligible adverse impacts upon cells, which jointly can improve the survival rate and mutagenic efficiency. Provided that banana is used for the aseptic proliferation of adventitious buds, even at a lower concentration, it could produce a higher effect because soaking can make the cell metabolism of adventitious buds active and sensitive to the applied mutagens. Here we found that $0.8 \% \mathrm{v} / \mathrm{v}$ EMS for $4 \mathrm{~h}$ was the optimal situation for inducing a high mutation frequency in the FJ shoot tips. We describe here the identification of a stably inherited mutant 'Refen 1' (RF1) with a semi-dwarfing phenotype and significantly better agronomic traits than the wild type (local cultivars).

Dwarfism is one of the most important objectives of banana breeding because dwarf plants have strong resistance to wind or flood disturbances (Cho et al., 2016; Wang et al., 2021). Recent work found that chemical mutagenesis is capable of inducing dwarf and semi-dwarf mutants from high-stem banana varieties (Aslam et al., 2016; Amosova et al., 2019). In our study, the gene locus controlling banana plant height was sensitive to the EMS mutagen, leading to abundant dwarf or semi-dwarf mutant offspring obtained. Hence, our approach provides a novel avenue for the semi-dwarf breeding of new banana varieties, yet the molecular mechanisms responsible for the dwarfism induced by EMS still await elucidation in future studies.

Excellent fruit quality is another key goal of banana breeding, and primary carbohydrate metabolites are essential determinants of fruit quality (Allegra et al., 2018). It is known that mutagens can induce further variation in quality traits, such as astringency, this being relatively easy to remove via mutagenesis (Shen et al., 2019). Banana is a typical climacteric fruit, one whose fruit-flavor quality is affected by a series of ripening processes that progress in tandem with the accumulation of soluble sugars. Sugar is the ultimate precursor for most quality-relevant components in the fruit of bananas, such as acids, pigments, tannins, and aroma volatiles (Hall et al., 2011). A high acid content often reduces fruit quality, though a moderate concentration of acid can improve the palatability of fruits (Liao et al., 2019). Therefore, the quality of a fruit and its taste are usually influenced by the sugar and acid contents or, more simply, by its sugar-to-acid ratio (Qiao et al., 2018). In our study, the EMS-induced mutant gained a RSTA in an efficient manner, in contrast to the long timespan needed to achieve that through traditional breeding.

Plant cell walls have critical biological roles in plant growth and development, such as the regulation of cell shape and expansion, ion exchange, and resistance to biotic or abiotic stresses. Recently, carbon partitioning was also characterized to function in regulating the biosynthesis of cell wall polysaccharides and the production of other carbohydrates, such as soluble sugars and starch (Fan et al., 2017, 2019). That the RF1 mutant harbors remarkably augmented levels of soluble sugars and starch accumulation, coupled with its significantly reduced cellulose deposition, strongly suggests that dynamic regulation of carbon partitioning is operating in this discovered banana mutant. Correspondingly, the considerable soluble sugar accumulation in the RF1 mutant is likely a major cause of its high resistance to cold stress, whereas the altered cell wall composition would contribute to its dwarf phenotype (Corneillie et al., 2019; Touchell et al., 2020; Madadi et al., 2021a,b).

\section{CONCLUSION}

Using classic EMS-induced mutagenesis, this study identified a novel banana RF1 mutant that has a typical semi-dwarf phenotype. Compared with local banana cultivars, the RF1 mutant showed significantly improved agronomic traits and enhanced tolerance to cold stress and resistance to Sigatoka disease. Chemical analyses further indicated that dynamic regulation of carbon partitioning should occur in the RF1 mutant to explain its remarkably augmented soluble sugars and starch accumulation and reduced cellulose deposition. Therefore, this study has not only demonstrated a genetic approach for selecting desirable bananas, but also enhanced our understanding of the genes controlling plant architecture, tolerance to cold and resistance to Sigatoka disease, and carbohydrate metabolism in bananas. Further work is now needed to examine the molecular mechanisms underlying the improved traits of the $R F 1$ mutant to develop genetically improved banana cultivars for widespread use. 


\section{DATA AVAILABILITY STATEMENT}

The original contributions presented in the study are included in the article/Supplementary Material, further inquiries can be directed to the corresponding author.

\section{AUTHOR CONTRIBUTIONS}

$\mathrm{XW}, \mathrm{AW}, \mathrm{YL}$, and JL conceived and designed the work. AW, YL, YX, QW, JW, FLin, DG, FLiu, and YW performed the experiments and carried out the analyses. $\mathrm{XW}, \mathrm{LP}$, and JL wrote the manuscript. All authors contributed to the article and approved the submitted version.

\section{FUNDING}

This work was financially supported by the Youth Foundation of Natural Science Foundation of Hainan Province (320QN306),

\section{REFERENCES}

Allegra, A., Gallotta, A., Carimi, F., Mercati, F., Inglese, P., and Martinelli, F. (2018). Metabolic Profiling and Post-harvest Behavior of "Dottato" Fig (Ficus carica L.) Fruit Covered With an Edible Coating From O. ficus-indica. Front. Plant Sci. 9:1321. doi: 10.3389/fpls.2018.01321

Altemimi, A., Lakhssassi, N., Baharlouei, A., Watson, D. G., and Lightfoot, D. A. (2017). Phytochemicals: extraction, isolation, and identification of bioactive compounds from plant extracts. Plants 6:42. doi: 10.3390/plants6040042

Amah, D., Biljon, A. V., Maziya-Dixon, B., Labuschagne, M., and Swennen, R. (2019). Effects of in vitro polyploidization on agronomic characteristics and fruit carotenoid content; implications for banana genetic improvement. Front. Plant Sci. 10:1450. doi: 10.3389/fpls.2019.01450

Amosova, A. V., Zoshchuk, S. A., Volovik, V. T., Shirokova, A. V., Horuzhiy, N. E., Mozgova, G. V., et al. (2019). Phenotypic, biochemical and genomic variability in generations of the rapeseed (Brassica napus L.) mutant lines obtained via chemical mutagenesis. PLoS ONE 14:e0221699. doi: 10.1371/journal.pone.0221699

AOAC (1990). "Official methods of analysis of the Association of Official Analytical Chemists," 15th/Ed. Washington, DC: Association of official analytical chemists.

Arinaitwe, I. K., Teo, C. H., Kayat, F., Tumuhimbise, R., Uwimana, B., Kubiriba, J., et al. (2019). Evaluation of banana germplasm and genetic analysis of an F-1 population for resistance to Fusarium oxysporum f. sp. cubense race. Euphytica 215:175. doi: 10.1007/s10681-019-2493-3

Arisha, M. H., Shah, S. N., Gong, Z. H., Jing, H., Li, C., and Zhang, H. X. (2015). Ethyl methane sulfonate induced mutations in M2 generation and physiological variations in M1 generation of peppers (Capsicum annuum L.). Front. Plant Sci. 6:399. doi: 10.3389/fpls.2015.00399

Aslam, U., Cheema, H. M. N., Ahmad, S., Khan, I. A., Malik, W., and Khan, A. A. (2016). COTIP: cotton TILLING platform, a resource for plant improvement and reverse genetic studies. Front. Plant Sci. 7:1863. doi: $10.3389 /$ fpls.2016.01863

Batte, M., Swennen, R., Uwimana, B., Akech, V., Brown, A., Tumuhimbise, R., et al. (2019). Crossbreeding East African highland bananas: lessons learnt relevant to the botany of the crop after 21 years of genetic enhancement. Front. Plant Sci. 10:81. doi: 10.3389/fpls.2019.00081

Bhagwat, B., and Duncan, E. J. (1998). Mutation breeding of banana cv. Highgate (Musa spp., AAA Group) for tolerance to Fusarium oxysporum f. sp. cubense using chemical mutagens. Sci. Hortic. 73, 11-22. doi: 10.1016/S0304-4238(97)00141-6

Bi, Y., Zhang, Y. Y., Jiang, H. H., Hong, Y., Gu, Z. B., Cheng, L., et al. (2017). Molecular structure and digestibility of banana flour and starch. Food Hydrocolloids 72, 219-227. doi: 10.1016/j.foodhyd.2017.06.003 the China Agriculture Research System of MOF and MARA (CARS-31-02), and the Lancang-Mekong Cooperation Special Fund.

\section{ACKNOWLEDGMENTS}

The authors thank the technical staff of the Haikou Xinhe agriculture farm (in Meilan town) and Guixing Agricultural Science and Technology Co. Ltd. (in Xingyi county), for managing the field trials.

\section{SUPPLEMENTARY MATERIAL}

The Supplementary Material for this article can be found online at: https://www.frontiersin.org/articles/10.3389/fpls.2021. 730718/full\#supplementary-material

Caldwell, D. G., McCallum, N., Shaw, P., Muehlbauer, G. J., Marshall, D. F., and Waugh, R. (2004). A structured mutant population for forward and reverse genetics in Barley (Hordeum vulgare L.). Plant J 40, 143-150. doi: 10.1111/j.1365-313X.2004.02190.x

Cheesman, E. E. (1947). Classification of the bananas: the genus Musa L. Kew Bull. 2, 106-117. doi: 10.2307/4109207

Cheng, Z. H., Yu, X., Li, S. X., and Wu, Q. (2018). Genome-wide transcriptome analysis and identification of benzothiadiazole-induced genes and pathways potentially associated with defense response in banana. BMC Genomics 19:454doi: 10.1186/s12864-018-4830-7

Cho, S. H., Kang, K., Lee, S. H., Lee, I. J., and Paek, N. C. (2016). OsWOX3A is involved in negative feedback regulation of the gibberellic acid biosynthetic pathway in rice (Oryza sativa). J. Exp. Bot. 67, 1677-1687. doi: $10.1093 / \mathrm{jxb} / \mathrm{erv} 559$

Chong, L. C., Cheng, L. H., and Aziz, A. A. N. (2011). Properties of polyphenol oxidase obtained fromMusa acuminata $\times$ balbisianaColla cv. "Pisang Awak" pulp and peel Propiedades de polifenoloxidasa obtenido de la pulpa y piel deMusa acuminata $\times$ balbisianaColla cv. "Pisang Awak". CyTA-J. Food 9, 25-30. doi: 10.1080/19476330903503379

Corneillie, S., De Storme, N., Van Acker, R., Fangel, J. U., De Bruyne, M., De Rycke, R., et al. (2019). Polyploidy affects plant growth and alters cell wall composition. Plant Physiol.179, 74-87. doi: 10.1104/pp.18. 00967

Datta, S., Jankowicz-Cieslak, J., Nielen, S., Ingelbrecht, I., and Till, B. J. (2018). Induction and recovery of copy number variation in banana through gamma irradiation and low-coverage whole-genome sequencing. Plant Biotechnol. J. 16, 1644-1653. doi: 10.1111/pbi.12901

de Deus, J. A. L., Neves, J. C. L., Corrêa, M. C. M., Parent, S. É., and Natale, W. (2018). Balance design for robust foliar nutrient diagnosis of "Prata" banana (Musa spp.). Sci. Rep. 8:15040. doi: 10.1038/s41598-01832328-y

Deneo-Pellegrini, H., De Stefani, E., and Ronco, A. (1996). Vegetables, fruits, and risk of colorectal cancer: a case-control study from Uruguay. Nutr. Cancer 25, 297-304. doi: 10.1080/01635589609514453

Fan, C., Feng, S., Huang, J., Wang, Y., Wu, L., Li, X., et al. (2017). AtCesA8-driven OsSUS3 expression leads to largely enhanced biomass saccharification and lodging resistance by distinctively altering lignocellulose features in rice. Biotechnol. Biofuels 10:221. doi: 10.1186/s13068-0170911-0

Fan, C. F., Wang, G. Y., Wang, Y. M., Zhang, R., Wang, Y. T., Feng, S. Q., et al. (2019). Sucrose synthase enhances hull size and grain weight by regulating cell division and starch accumulation in transgenic rice. Int. J. Mol. Sci. 20:4971. doi: 10.3390/ijms20204971 
FAOSTAT (Food and Agriculture Statistics) (2020). Availabe online at: http:// www.fao.org/food-agriculture-statistics/resources/publications/statisticalyearbook-and-pocketbook/en/.

Gao, R., Guo, G., Fang, C., Huang, S., Chen, J., Lu, R., et al. (2018). Rapid generation of barley mutant lines with high nitrogen uptake efficiency by microspore mutagenesis and field screening. Front. Plant Sci. 9:450. doi: $10.3389 /$ fpls.2018.00450

Ge, X. J., Liu, M. H., Wang, W. K., Schaal, B. A., and Chiang, T. Y. (2005). Population structure of wild bananas, Musa balbisiana, in China determined by SSR fingerprinting and cpDNA PCR-RFLP. Mol. Ecol. 14, 933-944. doi: 10.1111/j.1365-294X.2005.02467.x

Greene, E. A., Codomo, C. A., Taylor, N. E., Henikoff, J. G., Till, B. J., Reynolds, S. H., et al. (2003). Spectrum of chemically induced mutations from a large-scale reverse-genetic screen in Arabidopsis. Genetics 164, 731-740. doi: 10.1093/genetics/164.2.731

Griggs, D., Stafford-Smith, M., Gaffney, O., Rockström, J., Öhman, M. C., Shyamsundar, P., et al. (2013). Sustainable development goals for people and planet. Nature 495, 305-307. doi: 10.1038/495305a

Guo, L. J., Yang, L. Y., Liang, C. C., Wang, G. F., Dai, Q. D., and Huang, J. S. (2015). Differential colonization patterns of bananas (Musa spp.) by physiological race 1 and race 4 isolates of Fusarium oxysporum f.sp cubense. J. Phytopathol. 163, 807-817. doi: $10.1111 /$ jph. 12378

Gusta, L. V., and Wisniewski, M. (2013). Understanding plant cold hardiness: an opinion. Physiol. Plant. 147, 4-14. doi: 10.1111/j.1399-3054.2012.01611.x

Hall, G. E., Bondada, B. R., and Keller, M. (2011). Loss of rachis cell viability is associated with ripening disorders in grapes. J. Exp. Bot. 62, 1145-1153. doi: $10.1093 /$ jxb/erq355

Heslop-Harrison, J. S., and Schwarzacher, T. (2007). Domestication, genomics and the future for banana. Ann. Bot. 100, 1073-1084. doi: 10.1093/aob/mcm191

Hohmann, U., Jacobs, G., and Jung, C. (2005). An EMS mutagenesis protocol for sugar beet and isolation of non-bolting mutants. Plant Breed. 124, 317-321. doi: 10.1111/j.1439-0523.2005.01126.x

Hu, W., Zuo, J., Hou, X. W., Yan, Y., Wei, Y. X., Liu, J. H., et al. (2015). The auxin response factor gene family in banana: genome-wide identification and expression analyses during development, ripening, and abiotic stress. Front. Plant Sci. 6:742. doi: 10.3389/fpls.2015.00742

Huang, X., Lu, X. Y., Zhao, J. T., Chen, J. K., Dai, X. M., Xiao, W., et al. (2010). MaSERK1 gene expression associated with somatic embryogenic competence and disease resistance response in banana (Musa spp.). Plant Mol. Biol. Rep. 28, 309-316. doi: 10.1007/s11105-009-0150-z

Jain, S. M. (2010). Mutagenesis in crop improvement under the climate change. Rom. Biotechnol. Lett. 15, 88-106. doi: 10.1007/s11157-0109193-8

Jankowicz-Cieslak, J., Huynh, O. A., Brozynska, M., Nakitandwe, J., and Till, B. (2012). Induction, rapid fixation and retention of mutations in vegetatively propagated banana. Plant Biotechnol. J. 10, 1056-1066. doi: 10.1111/j.1467-7652.2012.00733.x

Jeridi, M., Perrier, X., Rodier-Goud, M., Ferchichi, A., Dhont, A., and Bakry, F. (2012). Cytogenetic evidence of mixed disomic and polysomic inheritance in an allotetraploid (AABB) Musa genotype. Ann. Bot. 110, 1593-1606. doi: $10.1093 / \mathrm{aob} / \mathrm{mcs} 220$

Karmarkar, V. M., Kulkarni, V. M., Suprasanna, P., Bapat, V. A., and Rao, P. S. (2001). Radio-sensitivity of in vivo and in vitro cultures of banana cv. Basrai (AAA). Fruits 56, 67-74. doi: 10.1051/fruits:2001114

Lee, Y. H., Park, W., Kim, K. S., Jang, Y. S., Lee, J. E., Cha, Y. L., et al. (2018). EMS-induced mutation of an endoplasmic reticulum oleate desaturase gene (FAD2-2) results in elevated oleic acid content in rapeseed (Brassica napus L.). Euphytica 214:12. doi: 10.1007/s10681-017-2106-y

Li, J., Liu, F., Yu, H., Li, Y., Zhou, S., Ai, Y., et al. (2021). Diverse banana pseudostems and rachis are distinctive for edible carbohydrates and lignocellulose saccharification towards high bioethanol production under chemical and liquid hot water pretreatments. Molecules 26:3870. doi: 10.3390/molecules 26133870

Li, M., Feng, S., Wu, L., Li, Y., Fan, C., Zhang, R., et al. (2014). Sugar-rich sweet sorghum is distinctively affected by wall polymer features for biomass digestibility and ethanol fermentation in bagasse. Bioresour. Technol. 167, 14-23. doi: 10.1016/j.biortech.2014.04.086
Liao, L., Dong, T., Qiu, X., Rong, Y., Wang, Z., and Zhu, J. (2019). Nitrogen nutrition is a key modulator of the sugar and organic acid content in citrus fruit. PLoS ONE 14:e0223356. doi: 10.1371/journal.pone.0223356

Lu, Y., Dai, S., Gu, A., Liu, M., Wang, Y., Luo, S., et al. (2016). Microspore induced doubled haploids production from ethyl methanesulfonate (EMS) soaked flower buds is an efficient strategy for mutagenesis in Chinese cabbage. Front. Plant Sci. 7:1780. doi: 10.3389/fpls.2016.01780

Madadi, M., Wang, Y., Xu, C., Liu, P., Wang, Y., Xia, T., et al. (2021a). Using Amaranthus green proteins as universal biosurfactant and biosorbent for effective enzymatic degradation of diverse lignocellulose residues and efficient multiple trace metals remediation of farming lands. J. Hazard. Mater. 406:124727. doi: 10.1016/j.jhazmat.2020.124727

Madadi, M., Zhao, K., Wang, Y., Wang, Y., Tang, S. W., Xia, T., et al. (2021b). Modified lignocellulose and rich starch for complete saccharification to maximize bioethanol in distinct polyploidy potato straw. Carbohydr. Polym. 265:118070. doi: 10.1016/j.carbpol.2021.118070

Meteorological Bureau of Guangxi Zhuang Autonomous Region China (2013). Technical Specifications for Cold Damage Assessment of Banana. Domestic Industry standard CN QX.

Moon, K. B., Ahn, D. J., Park, J. S., Jung, W. Y., Cho, H. S., Kim, H. R., et al. (2018). Transcriptome profiling and characterization of droughttolerant potato plant (Solanum tuberosum L.). Mol. Cells 41, 979-992. doi: 10.14348/molcells.2018.0312

Murashige, T. S., and Skoog, F. A. (1962). A revised medium for rapid growth and bioassays with tobaco tissue cultures. Physiol. Plant. 1, 437-496.

Naknaen, P., Charoenthaikij, P., and Kerdsup, P. (2016). Physicochemical properties and nutritional compositions of foamed banana powders (pisang awak, Musa sapientum L.) dehydrated by various drying methods. Walailak J. Sci. Tech. 13, 177-191. doi: 10.14456/wjst.2016.18

Oladosu, Y., Rafii, M. Y., Abdullah, N., Hussin, G., Ramli, A., Rahim, H. A., et al. (2015). Principle and application of plant mutagenesis in crop improvement: a review. Biotechnol. Biotechnol. Equip. 30, 1-16. doi: $10.1080 / 13102818.2015 .1087333$

Ono, H., Tesaki, S., Tanabe, S., and Watanabe, M. (1998). 6-Methylsulfinylhexyl isothiocyanate and its homologues as food-originated compounds with antibacterial activity against Escherichia coli and Staphylococcus aureus. Biosci. Biotechnol. Biochem. 62, 363-365. doi: 10.1271/bbb.62.363

Orjeda, G. (1998). Evaluation of Musa Germplasm for Resistance to Sigatoka Diseases and Fusarium wilt. Guidelines Technical INIBAP (INIBAP), Rome; Montpellier; Wageningen: International Plant Genetic Resources Institute; International Network for the Improvement of Banana and Plantain; ACP-EU Technical Centre for Agricultural and Rural Cooperation.

Ortiz, R., and Swennen, R. (2014). From crossbreeding to biotechnologyfacilitated improvement of banana and plantain. Biotechnol. Adv. 32, 158-169. doi: 10.1016/j.biotechadv.2013.09.010

Pattison, A. B., Wright, C. L., Kukulies, T. L., and Molina, A. B. (2014). Ground cover management alters development of Fusarium wilt symptoms in Ducasse bananas. Australas. Plant Pathol. 43, 465-476. doi: 10.1007/s13313-014-0296-5

Pearce, R. S. (1988). Extracellular ice and cell shape in frost-stressed cereal leaves: a low-temperature scanning-electron-microscopy study. Planta 175, 313-324. doi: 10.1007/BF00396336

Pegg, K. G., Coates, L. M., O’Neill, W. T., and Turner, D. W. (2019). The Epidemiology of Fusarium Wilt of Banana. Front. Plant Sci. 10:19. doi: $10.3389 /$ fpls.2019.01395

Peng, L. C., Hocart, C. H., Redmond, J. W., and Williamson, R. E. (2000). Fractionation of carbohydrates in Arabidopsis root cell walls shows that three radial swelling loci are specißcally involved in cellulose production. Planta 211, 406-414. doi: 10.1007/s004250000301

Perrier, X., De Langhe, E., Donohue, M., Lentfer, C., Vrydaghs, L., Bakry, F., et al. (2011). Multidisciplinary perspectives on banana (Musa spp.) domestication. Proc. Natl. Acad. Sci. U.S.A. 108, 11311-11318. doi: 10.1073/pnas.11020 01108

Qiao, X., Yin, H., Li, L., Wang, R., Wu, J., Wu, J., et al. (2018). Different modes of gene duplication show divergent evolutionary patterns and contribute differently to the expansion of gene families involved in important fruit traits in pear (Pyrus bretschneideri). Front. Plant Sci. 9:161. doi: $10.3389 /$ fpls.2018.00161 
Rames, E. K., Pattison, A. B., Czislowski, E., and Smith, M. K. (2018). Soil microbial community changes associated with ground cover management in cultivation of Ducasse banana (Musa sp. ABB, Pisang Awak subgroup) and suppression of Fusarium oxysporum. Australas. Plant Pathol. 47, 449-462. doi: $10.1007 /$ s13313-018-0578-4

Ranasinghe, L., Jayawardena, B., and Abeywickrama, K. (2002). Fungicidal activity of essential oils of Cinnamomum zeylanicum (L.) and Syzygium aromaticum (L.) Merr et L.M.Perry against crown rot and anthracnose pathogens isolated from banana. Lett. Appl. Microbiol. 35, 208-211. doi: 10.1046/j.1472-765X.2002.01165.x

Reyes-Borja, W. O., Sotomayor, I., Garzón, I., Vera, D., CedeÑo, M., Castillo, B., et al. (2007). Alteration of resistance to black Sigatoka (Mycosphaerella fijiensis Morelet) in banana by in vitro irradiation using carbon ion-beam. Plant Biotechnol. 24, 349-353. doi: 10.5511/plantbiotechnology.24.349

Samatadze, T. E., Zoshchuk, S. A., Hazieva, F. M., Yurkevich, O. Y., Svistunova, N. Y., Morozov, A. I., et al. (2019). Phenotypic and molecular cytogenetic variability in calendula (Calendula officinalis L.) cultivars and mutant lines obtained via chemical mutagenesis. Sci. Rep. 9, 9155-9155. doi: 10.1038/s41598-019-45738-3

Saraswathi, M. S., Uma, S., Kannan, G., Selvasumathi, M., Mustaffa, M. M., and Backiyarani, S. (2016). Cost-effective tissue culture media for large-scale propagation of three commercial banana (Musaspp.) varieties. J. Hortic. Sci. Biotechnol. 91, 23-29. doi: 10.1080/14620316.2015.1117227

Serrat, X., Esteban, R., Guibourt, N., Moysset, L., Nogues, S., and Lalanne, E. (2014). EMS mutagenesis in mature seed-derived rice calli as a new method for rapidly obtaining TILLING mutant populations. Plant Methods 10:5. doi: 10.1186/1746-4811-10-5

Shao, C., Xiang, D., Wei, H., Liu, S., Guo, L., Li, C., et al. (2020). Predicting Virulence of Fusarium Oxysporum f. sp. Cubense Based on the Production of Mycotoxin Using a Linear Regression Model. Toxins 12:254. doi: 10.3390/toxins12040254

Shen, Y., Zhuang, W., Tu, X., Gao, Z., Xiong, A., Yu, X., et al. (2019). Transcriptomic analysis of interstock-induced dwarfism in Sweet Persimmon (Diospyros kaki Thunb.). Hortic. Res. 6:51. doi: 10.1038/s41438-019-0133-7

Sima, T., Lee, A. T., Mohan, J. S., Mahbod, S., and Parisa, A. (2017). TILLING, highresolution melting (HRM), and next-generation sequencing (NGS) techniques in plant mutation breeding. Mol. Breed. 37:40. doi: 10.1007/s11032-017-0643-7

Smith, M. K., Daniells, J. W., Peasley, D., O’Neill, W., Samuelian, S., Wright, C., et al. (2018). Field evaluation of six Gros Michel banana accessions (Musa spp., AAA group) for agronomic performance, resistance to Fusarium wilt race 1 and yellow Sigatoka. Crop Prot. 113, 84-89. doi: 10.1016/j.cropro.2018.07.009

Takahashi, D., Johnson, K. L., Hao, P., Tuong, T., Erban, A., Sampathkumar, A., et al. (2021). Cell wall modification by the xyloglucan endotransglucosylase/hydrolase XTH19 influences freezing tolerance after cold and sub-zero acclimation. Plant Cell Environ. 44, 915-930. doi: $10.1111 /$ pce. 13953

Tigist, M., Workneh, T. S., and Woldetsadik, K. (2013). Effects of variety on the quality of tomato stored under ambient conditions. J. Food Sci. Technol. 50, 477-486. doi: 10.1007/s13197-011-0378-0

Touchell, D. H., Palmer, I. E., and Ranney, T. G. (2020). In vitro Ploidy Manipulation for Crop Improvement. Front. Plant Sci. 11:722. doi: 10.3389/fpls.2020.00722

Uma, S., Lakshmi, S., Saraswathi, M. S., Akbar, A., and Mustaffa, M. M. (2012). Plant regeneration through somatic embryogenesis from immature and mature zygotic embryos of Musa acuminata ssp burmannica. in vitro cell. Dev. Biol. Plant 48, 539-545. doi: 10.1007/s11627-012-9462-z

Vishnevetsky, J., White, T. L., Palmateer, A. J., Flaishman, M., Cohen, Y., Elad, Y., et al. (2011). Improved tolerance toward fungal diseases in transgenic Cavendish banana (Musa spp. AAA group) cv. Grand Nain. Transgenic Res. 20, 61-72. doi: 10.1007/s11248-010-9392-7

Wang, J. S., Wang, A. B., Ma, W. H., Xu, B. Y., Zang, X. P., Tan, L., et al. (2019). Comparison of physicochemical properties and in vitro digestibility of starches from seven banana cultivars in China. Int. J. Biol. Macromol. 121, 279-284. doi: 10.1016/j.ijbiomac.2018.09.140

Wang, W., Simmonds, J., Pan, Q. L., Davidson, D., He, F., Battal, A., et al. (2018). Gene editing and mutagenesis reveal inter-cultivar differences and additivity in the contribution of TaGW2homoeologues to grain size and weight in wheat. Theor. Appl. Genet. 131, 2463-2475. doi: 10.1007/s00122-018-3166-7

Wang, X., Yu, R., and Li, J. (2021). Using genetic engineering techniques to develop banana cultivars with fusarium wilt resistance and ideal plant architecture. Front. Plant Sci. 11:2202. doi: 10.3389/fpls.2020. 617528

Workneh, T. S., Osthoff, G., and Steyn, M. (2012). Effects of preharvest treatment, disinfections, packaging and storage environment on quality of tomato. J. Food Sci. Technol. 49, 685-694. doi: 10.1007/s13197-0110391-3

Wu, Z. L., Zhang, M. L., Wang, L. Q., Tu, Y. Y., Zhang, J., Xie, G. S., et al. (2013). Biomass digestibility is predominantly affected by three factors of wall polymer features distinctive in wheat accessions and rice mutants. Biotechnol. Biofuels 6:183. doi: 10.1186/1754-6834-6-183

Wyatt, L. E., Strickler, S. R., Mueller, L. A., and Mazourek, M. (2015). An acorn squash (Cucurbita pepo ssp. ovifera) fruit and seed transcriptome as a resource for the study of fruit traits in Cucurbita. Hortic. Res. 2:14070. doi: 10.1038/hortres.2014.70

Xu, M., Liu, X., Yu, L., Liu, S., Zeng, L., Chen, R., et al. (2010). Physiological analysis on mechanisms of cold-tolerance of Dongxiang wild rice (I). Agric. Sci. Technol. 11, 39-43. doi: 10.16175/j.cnki.1009-4229.2010.02.034

Yap, M., Fernando, W. M. A. D. B., Brennan, C. S., Jayasena, V., and Coorey, R. (2017). The effects of banana ripeness on quality indices for puree production. Lwt-Food Sci. Technol. 80, 10-18. doi: 10.1016/j.lwt.2017.01.073

Zhang, K., Guo, L., Cheng, W., Liu, B., Li, W., Wang, F., et al. (2020a). SH1dependent maize seed development and starch synthesis via modulating carbohydrate flow and osmotic potential balance. BMC Plant Biol. 20:264. doi: 10.1186/s12870-020-02478-1

Zhang, Y. W., Chen, W. X., Chen, H. M., Zhong, Q. P., Yun, Y. H., and Chen, W. J. (2020b). Metabolomics analysis of the deterioration mechanism and storage time limit of tender coconut water during storage. Foods 9:46. doi: 10.3390/foods9010046

Zhu, A., Zhang, Y., Zhang, Z., Wang, B., Xue, P., Cao, Y., et al. (2018a). Genetic dissection of qPCG1 for a Quantitative Trait Locus for Percentage of Chalky Grain in Rice (Oryza sativa L.). Front. Plant Sci. 9:1173. doi: 10.3389/fpls.2018.01173

Zhu, X., Li, Q., Li, J., Luo, J., Chen, W., and Li, X. (2018b). Comparative study of volatile compounds in the fruit of two banana cultivars at different ripening stages. Molecules 23:2456. doi: 10.3390/molecules23102456

Conflict of Interest: The authors declare that the research was conducted in the absence of any commercial or financial relationships that could be construed as a potential conflict of interest.

Publisher's Note: All claims expressed in this article are solely those of the authors and do not necessarily represent those of their affiliated organizations, or those of the publisher, the editors and the reviewers. Any product that may be evaluated in this article, or claim that may be made by its manufacturer, is not guaranteed or endorsed by the publisher.

Copyright (C) 2021 Wang, Wang, Li, Xu, Wei, Wang, Lin, Gong, Liu, Wang, Peng and Li. This is an open-access article distributed under the terms of the Creative Commons Attribution License (CC BY). The use, distribution or reproduction in other forums is permitted, provided the original author(s) and the copyright owner(s) are credited and that the original publication in this journal is cited, in accordance with accepted academic practice. No use, distribution or reproduction is permitted which does not comply with these terms. 